\title{
Informação e ensino: uma inter-relação possível
}

\author{
Information and teaching: a possible interrelation
}

\author{
Marcela Arantes Ribeiro \\ Doutoranda em Ciência da Informação \\ Universidade Federal de Rondônia \\ mar_arantes@hotmail.com \\ Maria Helena Pereira dos Santos \\ Graduada em Pedagogia \\ Faculdade Porto \\ mariahelenas36@hotmail.com
}

\section{Resumo}

A discussão envolvendo a produção e transformação da informação no ambiente escolar possibilita contribuir com a Ciência da Informação no fortalecimento à multidisciplinaridade entre as ciências. Destarte, este texto respalda a formação do aluno, usuário da informação, a partir da mediação desenvolvida pelas professoras colaboradoras da pesquisa, no sentido de contribuir para o ensinoaprendizado. $O$ presente trabalho tem como objetivo analisar a mediação da informação no ambiente escolar para formação do conhecimento do usuário crítico e atuante na sociedade. Os resultados, obtidos por meio da pesquisa exploratória de abordagem qualitativa, com aplicação de questionários, demonstra a importância da informação no ensino de Geografia e perpassa, ainda, pelo papel do professor como mediador na formação do conhecimento do aluno. A partir destes dados, concluise a importância de discutir, de forma interdisciplinar e social, a Ciência da Informação no âmbito do ensino.

\section{Palavras-Chave}

Ciências da Informação. Geografia. Professor.

\begin{abstract}
The discussion involving the production and transformation of information in the school environment makes it possible to contribute to Information Science in strengthening multidisciplinarity among the sciences. That said, it supports this text in the education of the student, user of the information, based on the mediation developed by the collaborating teachers of the research, in the sense of contributing to the teaching and learning. The present work aims to analyze the mediation of information in the school environment to form the knowledge of a critical user and active in society. The results, obtained through exploratory research with a qualitative approach, with the application of questionnaires, demonstrate information in the teaching of Geography and also permeates the role of the teacher as a mediator of the student's knowledge formation. Based on the data, he concludes that it is important to discuss information science in an interdisciplinary and social way in the context of teaching.
\end{abstract}

Keywords

Information Sciences. Geography. Teacher. 


\section{INTRODUÇÃO}

A formação do conhecimento perpassa pela relação da informação com a aprendizagem do sujeito. Partindo desse princípio, tem-se o ensino de Geografia, que é indispensável para a formação do aluno e cidadão em uma sociedade. Vale ressaltar, ainda, a discussão da educação como base de formação sociocultural do sujeito.

A inter-relação das reflexões sobre conhecimento, informação e ensino possibilita ao sujeito interpretar o mundo em que vive, decifrar o ambiente em que se encontra, bem como, compreender os acontecimentos histórico-socioculturais como elementos da convivência social e do contentamento das suas necessidades.

A partir dessa abordagem, percebe-se a importância deste texto em reconhecer a inter-relação entre informação, conhecimento e ensino de Geografia pelo viés da mediação, o que contribui diretamente para formação do usuário da informação com o objetivo de ser um cidadão atuante na sociedade.

Entende-se que o ensino de Geografia possibilita a construção de um conhecimento reflexivo na vida de cada indivíduo, motivo pelo qual a disciplina é trabalhada desde as séries iniciais, contribuindo para a formação do pensamento crítico em crianças e jovens.

Assim, esse texto ao considerar a mediação no processo de aprendizagem, identifica a prática de ensino trabalhada pelas professoras colaboradoras da pesquisa com os alunos do Ensino Fundamental de uma determinada escola de Porto Velho, Rondônia, com a finalidade de desenvolver suas potencialidades no sentido de que sejam capazes de refletir sobre a informação e atuar, modificar e tomar decisões em benefício da sociedade em que vivem.

Por isso, ao estudar e discutir a importância da informação para a formação do conhecimento do aluno ainda no ensino básico, pelo viés da Ciência da Informação, percebe-se ser um caminho ainda pouco percorrido. Nesse cenário atual, este escrito apresenta uma discussão inicial que perpassa pelo questionamento principal: como a mediação da informação, ao considerar o ensino da Geografia, pode ser influenciadora direta na formação do cidadão, de maneira crítica e atuante?

Ao questionar a importância da formação do cidadão voltada para o meio social onde se vive, essa pesquisa tem como objetivo principal refletir sobre a mediação da informação, no ambiente escolar, para formação do conhecimento de um aluno crítico capaz de tomar decisões e atuar na sociedade.

Dessa forma, demonstra também uma análise reflexiva sobre a informação, o processo de ensino aprendizagem e o ensino de Geografia que perpassa pela compreensão de ensinar de forma crítica, ressaltando a importância de os alunos perceberem como está sendo construído o conhecimento. Tal abordagem considera, atualmente, o aluno como usuário da informação e participante ativo das transformações da sociedade. Tais mudanças ocorrem considerando as ações pautadas nas experiências individuais e coletivas do sujeito.

Assim, a inter-relação mediação da informação, conhecimento e educação proporciona refletir e demonstrar a possibilidade de formação do aluno, usuário da informação, que possa atuar na sociedade considerando a aprendizagem e o meio onde vive.

\section{INFORMAÇÃO, SOCIEDADE E ENSINO: UMA BREVE REFLEXÃO}

A sociedade modifica-se quando as pessoas que nela vivem criam suas demandas e necessidades a partir das relações sociais com o meio (SANTOS, 2008), ampliando sua percepção 
de ver o mundo, situação que conduz as transformações no comportamento social e, consequentemente, na sociedade.

Em meio a essa complexidade sociocultural, tem-se a informação como elemento de inter-relação entre as pessoas e/ou instituições que influencia diretamente nas relações sociais (FROHMANN, 2013).

Há uma discussão sobre informação no momento que se compreende as relações sociais envolvidas nesse processo. Há de se destacar ainda que essas relações apresentam dois lados explícitos. Ainda sobre essas relações, seus lados estão, predominantemente, envolvidos na produção do conhecimento, onde aquele que inicia a construção de uma informação determina o que será construído, a fim de permanecer no controle do segundo.

Nesse processo, tem-se a mediação de forma dinâmica envolvendo explicitamente os dois lados da informação. Nesta discussão, compreende-se ainda que a informação ultrapassa a linearidade e, quando compreendida de forma coletiva, torna-se possível identificar as interações dos indivíduos com outros meios.

A comunicação informacional necessita de uma mediação eficiente, assim os indivíduos envolvidos no processo devem propiciar uma dinâmica de retroalimentação constante. Portanto, o conhecimento coletivo e o conhecimento individual são frutos das interações entre os indivíduos e também das interações entre os indivíduos e os sistemas de informação. (FABEL at al., 2010, p. 16).

A partir dessa citação, considera-se a discussão no âmbito das relações sociais e culturais, onde há de se ponderar a analogia direta entre a informação e o conhecimento, pois, "A geração de 'novo' conhecimento somente é possível quando a informação é apropriada pelo indivíduo, por meio do estabelecimento de relações cognitivas." (FABEL et al., 2010, p. 14, grifo dos autores).

Percebe-se a inter-relação entre cognição, apropriação da informação, conhecimento e sujeito, sendo este último a base para a construção do novo conhecimento. Pode-se compreender, então, que as ações do sujeito na sociedade serão conduzidas pela inter-relação entre esses elementos.

Nesse âmbito de discussão, considera-se ainda o argumento de consolidação e desdobramento de uma informação, conforme esclarece Burke (2003, p. 17, grifo do autor):

\footnotetext{
Precisamos distinguir entre conhecimento e informação, "saber como" e "saber o quê", e o que é explicito e o que é tido como certo. Por uma questão de conveniência, este livro usará o termo "informação" para referir-se ao que é relativamente "cru", específico e prático, e "conhecimento" para denotar o que foi "cozido", processado ou sistematizado pelo pensamento.
}

Enfatizando a reflexão do autor, torna-se possível entender o conhecimento como o pensamento resultante da relação. Essa se estabelece entre o sujeito que conhece a informação, os mecanismos que serão propagados e o resultado da sistematização pelo pensamento.

Assim, compreende-se que o sujeito é o ser humano e a informação é parte da realidade com a qual se convive. Nesses termos, pode-se afirmar que "A informação é fabricada por indivíduos a partir de sua experiência passada e de acordo com as exigências de determinada situação na qual a informação deve ser usada." (CHOO, 2003, p. 83).

Compreende-se que o processo para consolidação e permanência de uma determinada informação perpassa pela experiência de vida de cada usuário, logo o processamento dessa informação, ao gerir um significado contextualizado, conduz ao conhecimento. Sendo assim, 
"Pode-se dizer que é o processamento da análise que converte a informação relativamente crua em conhecimento efetivo." (BURKE, 2012, p. 68).

Desta forma, nota-se que o conhecimento não nasce do vazio e sim das experiências que os sujeitos acumulam durante suas vivências e considerando a transmissão de geração para geração (LARAIA, 2004), bem como as leituras de livros e artigos diversos.

Compreende-se que o conhecimento é diferente de informação, é uma reflexão sobre a informação e seu processamento social. Dessa forma, pontua-se que a partir do momento em que se tem a junção dos múltiplos fragmentos da informação, processado e transformado em conhecimento, poderá ser sobreposto a partir de uma nova compreensão, pois "O conhecimento envolve o estabelecimento de relações entre informações isoladas." (ROSINI, 2012, p. 127). Ressalta-se novamente que tais ações consideram ainda o contexto social em que os usuários estão inseridos.

Considerando essa reflexão, Carvalho (2010, p. 20) esclarece:

[...] apropriação de informação nos despertou interesse, uma vez que trabalha no cerne da questão ao apontar que o indivíduo é parte central de qualquer processo informacional. Significa dizer que para qualquer uso informacional, o sujeito deve estar no centro, já que será o responsável pela transformação da informação em conhecimento.

Dessa forma, compreende-se o sujeito como usuário da informação e fundamental para construção do conhecimento. Nesse sentido, torna-se importante compreender o contexto sociocultural no qual está inserido, pois a informação somente ganhará sentido e significado se for acessível e compatível com a realidade do usuário.

\subsection{Uma informação importante: o ensino da Geografia Crítica}

A Geografia tem um novo conceito, uma nova informação a ser trabalhada nas escolas, onde os alunos estarão construindo o conhecimento sobre o mundo.

Essa construção deve ocorrer a partir de situações que perpassam a realidade vivida pelo aluno, colocando-os diante de situações de seu cotidiano e trazendo inquietações e perguntas que possibilitem o questionamento (VESENTINI et al., 1989).

O ensino de Geografia deve adentrar outros campos do conhecimento, quando necessário, objetivando a formação crítica do aluno. Nesse sentido e considerando a formação da ciência geográfica, Amorim Filho (2007, p. 17) afirma que "O que se consta é uma grande pluralidade no pensamento e na prática da Geografia.". Esta pluralidade apresenta-se na formação do pensamento geográfico, no momento que identifica diferentes teorias e métodos aplicados a ela.

Assim, a Geografia diretamente relacionado à sociedade vem mediando o aprendizado do aluno a partir de uma Geografia Crítica e plural, apresentando múltiplos olhares e caminhos para compreender o espaço socialmente construído (AMORIM FILHO, 2007).

A Geografia Crítica pode ser compreendida como parte de uma disciplina revolucionária formadora do cidadão questionador em oposição a uma visão de uma Geografia como sendo tradicional, de explicação objetiva e quantitativa, onde só se buscavam as respostas gerais das interpretações, sendo levada com neutralidade. (DINIZ FILHO, 2009).

A par de tais considerações, sabe-se que somente a partir dos anos 60 a Geografia Crítica começa a ter importância maior na sociedade. Quando os geógrafos passaram a estudar uma geografia relacionada às relações de trabalho, sociedade e natureza, para distribuição 
igualitária das condições necessárias da sociedade no lugar onde se vive, trazendo em evidências as lutas sociais. (DINIZ FILHO, 2009).

Pode-se compreender que essa ressignificação da informação no ensino da Geografia é aplicada de forma mais abrangente, ultrapassando a questão espacial e adentrando a relevância social. Nesse sentido, Menezes e Chiapetti (2015, p. 238) defendem que, "Ao pensarmos o ensino de Geografia para a formação de uma sociedade com indivíduos que pensam criticamente, estaremos automaticamente construindo um foco na formação do cidadão.".

Assim, um ensino crítico possibilita a formação de uma sociedade mais justa, igualitária, onde se possam tomar decisões corretas, em cima de conhecimentos construídos de situações do cotidiano e de uma necessidade real.

Por isso, ao perpassar pela discussão da Geografia Crítica voltada ao desenvolvimento de uma cidadania mais reflexiva (DINIZ FILHO, 2009), pode-se compreender como papel fundamental, no âmbito do ensino, possibilitar ao aluno o conhecimento do mundo, se colocando diante dele e integrando sobre o meio.

Portanto, a informação analisada como um fenômeno sociocultural, somente terá sentido se transitada e vivenciada na sociedade, por isso a inter-relação dessa discussão no âmbito do ensino de Geografia, onde há compreensão do funcionamento e da circulação da informação na sociedade, conduz para apropriação social do conhecimento da Geografia como elemento de mudanças sociais.

\subsection{Didática: uma mediação para o ensino}

O ato de ensinar e conduzir para a apropriação da informação ocorre a partir de todos os instrumentos informacionais com múltiplas linguagens possíveis. Compreende-se que ensinar é tornar o outro capaz de construir seu conhecimento que ocorre no mecanismo dialético com perguntas, sugestões e desafios.

O processo de aprendizagem acontece diariamente e, de alguma forma, a apropriação da informação acompanha esse processo. A educação na escola tem a finalidade de formar indivíduos preparados para a vida social, orientados para realidade espacial onde estão inseridos, como afirma Libâneo (1994, p. 24)

\footnotetext{
[...] a atividade educativa acontece nas mais variadas esferas da vida social (nas famílias, nos grupos sociais, nas instituições educacionais ou assistenciais, nas associações profissionais, sindicais e comunitárias, nas igrejas, nas empresas, nos meios de comunicação de massa etc.) e assume diferentes formas de organização. A educação escolar constitui-se num sistema de instrução e ensino com propósitos intencionais, práticas sistematizadas e alto grau de organização, ligado intimamente às demais práticas sociais. Pela educação escolar democratizam-se os conhecimentos, sendo na escola que os trabalhadores continuam tendo a oportunidade de prover escolarização formal aos seus filhos, adquirindo conhecimentos científicos e formando a capacidade de pensar criticamente os problemas e desafios postos pela realidade social.
}

Nota-se outro fator importante na apropriação da informação: os múltiplos espaços de vivência do sujeito. Tal situação parte do princípio de que na interação ocorre a consolidação da informação e, ao considerar a transição do indivíduo entre espaços, as informações são sobrepostas gerando e expandindo pensamento e comportamentos sociais. 
Nesse universo, como pontua o autor citado acima, a educação escolar torna-se complexa e intimamente ligada às práticas sociais, uma vez que há a responsabilidade de democratizar o conhecimento e formar cidadãos.

A partir dessa discussão, compreende-se que os conhecimentos científicos e a capacidade de pensar criticamente do aluno, também, são desenvolvidos na escola. Destaca-se, também, que além da escola o aluno perpassa outros locais de vivência. No que diz respeito a essa situação, a Lei de Diretrizes e Bases (LDB) estabelece:

Art. 1ㅇ A educação abrange os processos formativos que se desenvolvem na vida familiar, na convivência humana, no trabalho, nas instituições de ensino e pesquisa, nos movimentos sociais e organizações da sociedade civil e nas manifestações culturais. (BRASIL, 1996).

Novamente, pode-se perceber a ênfase na convivência, na interação, para que ocorra a educação. Destaca-se ainda que o ensino se dá mediante processos formativos que envolvem todos os meios de vivência sociocultural do cidadão.

Diante dessa complexidade e com objetivo de conduzir o processo de aprendizagem para que haja a apropriação da informação por parte do aluno, há de se considerar uma discussão sobre didática, pois esta "[...] estuda a técnica de ensino em todos os seus aspectos práticos e operacionais." (PILETTI, 2004, p. 47).

Por isso, é necessário que o professor tenha didática para que possa cumprir os objetivos da atividade docente no âmbito da formação do conhecimento. Nessa reflexão, Libâneo (1994, p. 28, grifo do autor) diz: "A Didática se caracteriza como mediação entre as bases teórico-científicas da educação escolar e a prática docente. Ela opera como que uma ponte entre o 'o quê' e o 'como' do processo pedagógico escolar.".

Nessa perspectiva sobre a didática como mediação, é demonstrada sua importância no processo de ensino-aprendizagem, bem como na apropriação da informação por parte do aluno. Este processo se dá por meio das bases teórico-científicas e da metodologia utilizada pelo professor, bem como das estratégias no tratamento do conteúdo e suas atividades didáticas.

Ainda na reflexão sobre didática e mediação, ressalta-se que, além das metodologias utilizadas em sala de aula, o professor tem como instrumento de uso diário o livro didático. Sobre esse assunto Vesentini (1997, p. 16, grifo do autor) argumenta:

[...] Contudo, é possível manter uma outra relação com o livro didático. O professor deve e pode encarar o manual não como o definidor de todo o seu curso, de todas as suas aulas, mas como um instrumento que está a seu serviço, a serviço de seus objetivos, e respostas de trabalho. Trata-se de usar criticamente o manual, relativizando-o, confrontando-o, com outros livros, com informações de jornais e revistas, com a realidade circundante. Ao invés de aceitar a "ditadura" do livro didático, o bom professor deve ver nele (assim como em textos alternativos, em slides, filmes, em obras paradidáticas etc.) tão somente um apoio ou complemento para a relação ensino-aprendizagem que visa integrar criticamente o educando ao mundo.

Diante da argumentação do autor, compreende-se o livro didático como um manual norteador, um dos instrumentos de trabalho utilizado pelo professor, ultrapassando a ideia de limitador e único objeto de ensino. Para mediar o processo de formação do conhecimento, o próprio autor sugere buscar outros materiais para confrontar ou complementar o livro didático, cita os jornais e as revistas ou mesmo outros textos teóricos envolvendo pesquisas 
realizadas pelos alunos. Dessa forma, conduz o ensino para uma possibilidade de formação de cidadãos críticos.

Considerando ainda a citação acima, tem-se o professor conduzido por uma didática de mediação, conforme Libâneo (1994), pois consegue interagir com o aluno e buscar apoios pedagógicos que complementem a formação do seu discente considerando o mundo em que esse está inserido. Por fim, o professor não precisa se limitar somente para os conteúdos do livro, podendo utilizar outros recursos na aula, deixando-a mais instigante aos alunos e, ao mesmo tempo, trazendo novos métodos para uma aprendizagem mais significativa a todos.

\section{PROCEDIMENTOS METODOLÓGICOS: UM CAMINHO TRAÇADO}

Ao discutir a caminhada para construção da pesquisa, parte-se do princípio de que esta possibilita a construção do conhecimento científico. Assim:

Pode-se definir pesquisa como o procedimento racional e sistemático que tem como objetivo proporcionar respostas aos problemas que são propostos. A pesquisa é requerida quando não se dispõe de informação suficiente para responder ao problema, ou então quando a informação disponível se encontra em tal estado de desordem que não possa ser adequadamente relacionada ao problema. (GIL, 2002, p. 17).

Pesquisar é importante para descobrir o novo, onde o conhecimento individual com o coletivo possibilita a construção do pensar e do agir sobre o mundo. Nesse sentido, esta pesquisa foi elaborada por meio de processos e fases que se estruturam com a formulação da problemática até a apresentação dos dados.

Este texto é resultado da releitura da pesquisa de campo realizada no ano de 2015 que apresentava como objetivo geral analisar o ensino da Geografia Crítica nas escolas pelas professoras do 5o ano do Ensino Fundamental, a partir da compreensão das educadoras sobre este ensino. Ressalta-se ainda que a intenção de expor uma discussão sobre a importância de inter-relacionar a informação, a mediação e o ensino de Geografia possibilita transversalizar a Ciência da Informação juntamente com os conhecimentos já existentes.

Esta pesquisa caracteriza-se como exploratória, fundamentada nas concepções de Gil (2002, p. 41), ao afirmar que "[...] estas pesquisas têm como objetivo principal o aprimoramento de ideias ou a descoberta de intuições [...]". Nesse sentido, se fez necessário durante a realização do trabalho de campo fazer a aproximação com a problemática, a saber: como a mediação da informação sobre a Geografia pode ser influenciadora direta na formação do cidadão, de forma crítica e atuante?

Ainda nessa fase da pesquisa, realizou-se o levantamento bibliográfico, o qual foi revisado no ano de 2020, e a aplicação dos questionários com professoras experientes no Ensino Fundamental e que vivenciam o problema pesquisado. A pesquisa contou a colaboração de quatro professoras do 50 ano do Ensino Fundamental. A partir da experiência dessas profissionais, foi possível inter-relacionar a Ciência da Informação com o processo de ensino e aprendizagem da Geografia, considerando ainda a formação do conhecimento do aluno, pelo viés da apropriação da informação.

A coleta de dados iniciou com o levantamento do material para revisão bibliográfica envolvendo a mediação da informação e o ensino de Geografia, conforme o fluxograma presente na Figura 1. 
Figura 1 - Fluxograma da Pesquisa

\section{Leitura bibliográfica}

Ocorreu em dois momentos: pesquisa de forma geral sobre o assunto pela Internet; direcionamento para artigos científicos e livros que abordassem sobre o assunto, concomitante ao fichamento de autores que fundamentavam o objetivo da pesquisa.

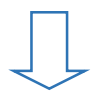

\section{Escrita do trabalho}

Ocorreu durante todo o processo de construção do trabalho, perpassando inicialmente pela construção da revisão bibliográfica, seguida da construção dos procedimentos metodológicos e finalizando com a análise dos dados.

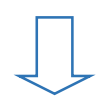

\section{Pesquisa de campo}

Apresenta como instrumento de pesquisa o questionário aplicado em uma escola da rede privada, onde uma das autoras exercia, na época da pesquisa, a função de professora auxiliar, situação que possibilitou o diálogo prévio, a execução da pesquisa e o diálogo com as colaboradoras da pesquisa.

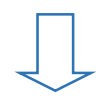

Análise de dados

Foi possível estudar a percepção de cada professora sobre o ensino da Geografia Crítica e inter-relacionar as respostas com o objetivo da pesquisa.

Fonte: Organizado pelas autoras (2020).

A pesquisa de campo foi realizada em uma instituição pública de direito privado ${ }^{1}$ que tem como objetivo contribuir para a construção de uma sociedade mais justa e para a melhoria da qualidade de vida dos cidadãos, prioritariamente de baixa renda, por meio de serviços subsidiados e de excelência. Tem como principal objetivo atuar no Estado de Rondônia sendo referência da prática do Serviço Social. É uma Instituição de ensino que atende tanto à população da capital, como à do interior em suas unidades.

Por se tratar de uma pesquisa que visa inter-relacionar a concepção de mediação com o ensino de Geografia, a abordagem do problema deu-se de forma qualitativa, o que permitiu um aprofundamento na questão estudada. Considera-se que a interpretação, por parte do pesquisador, é o principal caminho de investigação onde há o contato direto e prolongado entre os envolvidos na pesquisa (ALVES, 1991; GOLDENBERG, 1999). Tal situação enriqueceu a pesquisa, pois possibilitou captar os significados dos comportamentos das colaboradoras da pesquisa, bem como o ambiente observado.

Por se tratar de pesquisa exploratória de abordagem qualitativa, elegeu-se como instrumentos de coleta de dados o questionário, pois é uma técnica de investigação com "[...] questões apresentadas por escrito às pessoas, tendo por objetivo o conhecimento de opiniões, crenças, sentimentos, interesses, expectativas, situações vivenciadas etc.". (GIL, 1999, p. 128).

Durante o trabalho de campo, foi feita uma prévia conversa com as professoras apresentando a pesquisa. Iniciou-se a conversa sobre o ensino de Geografia na atualidade e a im-

\footnotetext{
${ }^{1}$ Optou-se por manter o anonimato da Instituição, considerando que o objeto dessa pesquisa é o ensino.
} 
portância desta para compreender o mundo em que o aluno vive. Nessa perspectiva, tem-se a Geografia Crítica que, além de conduzir para a compreensão, possibilita o questionamento do mundo em que em que vive, incluindo as relações que o aluno tem com o meio em que vive.

Os questionários foram entregues no mesmo dia às professoras do 5o ano do Ensino Fundamental, sendo duas no turno matutino e duas no turno vespertino. A devolutiva ocorreu em dias diferentes, pois cada uma necessitava de um tempo para concluir.

Para análise de dados, utilizaremos a identificação das docentes com letras, sendo denominadas como professora " $A$ "; " $B$ ", " $C$ " e " $D$ ", mantendo a identidade preservada, considerando que o objeto da pesquisa é a inter-relação entre Mediação e o ensino, o ato de ensinar.

Ressalta-se que as leituras bibliográficas sobre os temas abordados foram realizadas em todas as fases da construção do trabalho. Outro ponto importante refere-se ao trabalho de campo; registra-se que a aplicação do questionário respeitou o tempo e a disponibilidade de cada professora, bem como manteve-se na íntegra as respostas para fins de análise.

\section{RESULTADOS DA PESQUISA}

A possibilidade de considerar a apropriação da informação com base na discussão cognitiva, onde o meio sociocultural influenciará diretamente na percepção e compreensão do usuário, tem-se o ambiente escolar e o ensino de Geografia, pois por meio de seu conteúdo "[...] alteramos, modificamos, transformamos nosso conhecimento." (FADEL et al., 2010, p. 1718). Compreende-se que, a partir da construção do conhecimento, o aluno se relacionará com o meio modificando, tanto as relações socioculturais como a relação individual com o espaço físico de vivência.

Aproximando-se dessa discussão, tem-se a linha histórica da Ciência da Informação, a partir da noção de informação, pois "Aí se constitui a especificidade da Ciência da Informação: não o estudo de um novo objeto empírico, mas a análise dos mesmos fenômenos já estudados por outras ciências, a partir de um ponto de vista diferente, a partir de um olhar informacional." (ARAÚJO, 2014, p. 8).

Ao possibilitar uma abordagem dos mesmos fenômenos com ponto de vista diferente, permite-se a inter-relação com a Geografia no ambiente escolar. Nessa discussão ressalta, ainda, que "[...] muita informação vem em fragmentos, e uma parte do processo de produção do conhecimento consiste em encaixar e juntar esses fragmentos como se fossem um quebracabeça [...]" (BURKE, 2012, p. 78), por isso a importância dos professores como mediadores da informação para o aprendizado.

Assim, considerando o autor acima, pode-se compreender que o educador atuará na condução do processo de juntar os fragmentos para produção do conhecimento, seja no âmbito individual ou coletivo. A escola, com o método de ensino e os procedimentos instrucionais dos professores, possibilita o processo de produção do conhecimento visto esse como ferramenta que capacita os alunos a pensar de forma mais consciente, crítica e humana.

Com base nessa compreensão, o ensino de Geografia, nos anos iniciais, mostra-se uma tarefa importante para que na sociedade possa ser formada por cidadãos críticos, participativos e sujeitos de sua história. Nesse contexto, a formação do cidadão precisará contar com a atuação diferenciada do professor. Desta forma, torna-se importante que o educando tenha consciência de que faz parte do meio e que pode interagir de forma crítica e participativa na sociedade. Cabe ao professor, ainda nas séries iniciais, ser o mediador neste processo de formação do conhecimento pelo aluno, procurar estratégias e articular os seus componentes: objetivo, conteúdos, metodologia de ensino e avaliação. 
Assim, os resultados da pesquisa evidenciam a influência de um ensino de Geografia Crítica na formação do aluno, conforme representadas no Quadro 1.

Quadro 1 - Influência do ensino de Geografia crítica na formação atual dos alunos

\begin{tabular}{|c|l|}
\hline Professora & \multicolumn{1}{c}{ Percepção } \\
\hline A & $\begin{array}{l}\text { Pensar sobre as diversas questões sobre a relação da formação de território e o homem } \\
\text { que o habita permite a compreensão de seu modo de vida e como poderá realizar, quando } \\
\text { necessário, intervenções. }\end{array}$ \\
\hline B & $\begin{array}{l}\text { O ensino de Geografia deve levar o aluno à compreensão do lugar onde ele vive. Ela é um } \\
\text { saber de caráter estratégico que não se serve apenas para educar o cidadão, mas também } \\
\text { para ajudá-lo a mudar e compreender o seu meio e o mundo globalizado. }\end{array}$ \\
\hline C & $\begin{array}{l}\text { Possibilitando o desenvolvimento do senso crítico de cada aluno, completando o processo } \\
\text { de aprendizagem. }\end{array}$ \\
\hline D & $\begin{array}{l}\text { Pode influenciar em suas decisões futuras como cidadão crítico e com certeza irá pensar } \\
\text { em suas decisões colocadas por seus governantes. }\end{array}$ \\
\hline
\end{tabular}

Fonte: Dados da pesquisa (2015).

Ao analisar as respostas apresentadas, destacam-se os atos de pensar, compreender, possibilitar e, por fim, influenciar decisões. Para que tais situações acontecessem foi possível notar que as professoras de fato procuraram conduzir o aprendizado para que ocorresse a apropriação da informação por parte dos alunos, ou seja, "[...] uma apropriação voluntária e involuntária, consciente e inconsciente." (FADEL at al., 2010, p. 18).

Destaca-se o fragmento da resposta da Professora $D$, quando aborda a tomada de decisões futuras por parte dos alunos, por isso a importância de formar cidadão crítico para que possa de fato influenciar na sociedade. Considera-se que nesse processo a informação tornase elemento fundamental tanto para a formação do aluno quanto para sua tomada de decisão na sociedade.

Ainda com base no Quadro 1, nota-se ser importante desenvolver o espírito crítico no aluno, mostrar outras realidades e alternativas, o orientando para que perceba um mundo onde as transformações acontecem com muita rapidez e que ele pode se posicionar diante do mesmo. Moreira (2007, p. 105) é claro quando diz:

A Geografia é uma forma de leitura do mundo. A educação escolar é um processo no qual o professor e seu aluno se relacionam com o mundo através das relações que travam entre si, na escola e nas ideias. A Geografia e a educação formal concorrem para o mesmo fim de compreender e construir o mundo a partir das ideias que formam dele.

As respostas das professoras A, B, C e D coincidem com a fala do autor acima sobre a Geografia Crítica, pois essa orienta e influencia na formação dos alunos, possibilitando para todos os fins a compreensão de mundo e a construção, desenvolvimento, do senso crítico.

Tal reflexão possibilita ainda considerar o aluno, na concepção contemporânea, como "[...] usuários da informação têm buscado analisar as necessidades de informação presentes nas atividades cotidianas dos sujeitos [...]" (ARAÚJO, 2014, p. 131). Nesse sentido, a professora " $A$ " pontua que o ensino de Geografia: "[...] permite a compreensão de seu modo de vida $e$ como poderá realizar, quando necessário, intervenções." (PROFESSORA A, 2015).

Ainda defendendo o ensino a partir das atividades cotidianas dos alunos, destaca-se a resposta da Professora B, sobre a relação do ensino e a compreensão do cotidiano do aluno, 
por afirmar: "O ensino de Geografia deve levar o aluno à compreensão do lugar onde ele vive.". (PROFESSORA B, 2015).

Nesse sentido, "Entendemos que a construção do conhecimento dá-se individualmente, embora, necessariamente na relação com o mundo [...]" (FADEL et al., 2010, p. 18), por isso, ao trabalhar o lugar onde o aluno vive, propicia a interação com o mundo, com a informação e, consequentemente, com a construção do conhecimento.

Percebe-se que a Geografia, na escola e no período de realização da pesquisa, é mediada pelas professoras de forma clara quanto à compreensão da formação do aluno como cidadão atuante na sociedade. Podendo ser uma ação compreendida como "[...] mediação explícita, por seu lado, ocorre nos espaços em que a presença do usuário é inevitável [...]" (ALMEIDA JÚNIOR, 2009, p. 93). Neste ponto, adapta-se a concepção de mediação da informação para o ambiente escolar que possibilitou identificar a disciplina de Geografia como sendo não apenas mais uma disciplina na grade curricular, mas trazendo as compreensões que se fazem necessárias para a construção do conhecimento de cada aluno.

Na concepção de mediação no ambiente escolar e compreendendo a relação do processo de ensino-aprendizagem, o fragmento de resposta da Professora $\mathrm{C}$ pontua que a formação do conhecimento do aluno conduzida pela escola acaba: "Possibilitando o desenvolvimento do senso crítico de cada aluno, completando o processo de aprendizagem." (PROFESSORA C, 2015).

Ainda nesta compreensão, ressalta-se que o ensino de Geografia Crítica possibilita a formação do cidadão atuante na sociedade e, para tanto, se faz necessário que o aluno como usuário da informação ao "[...] possuir distintas opções de acesso à informação dará preferência àquela que for mais acessível ou com a qual mais se identificar [...]" (FADEL et al., 2010, p. 26).

No sentido de possibilitar ao aluno a identificação com a informação, a Professora B reporta ao ensino de Geografia por compreender que: "Ela é um saber de caráter estratégico que não se serve apenas para educar o cidadão, mas também para ajudá-lo a mudar e compreender o seu meio e o mundo globalizado." (PROFESSORA B, 2015).

A formação de um aluno cidadão torna-se o ponto central, na fala das professoras colaboradoras da pesquisa, conforme Quadro 1. É possível notar, então, que "[...] a preocupação principal deve ser a construção de uma ambiência para narrativa levando em conta que o imaginário e o prazer estético são fundamentais aos indivíduos em qualquer faixa etária." (BORTOLIN; ALMEIDA JÚNIOR, 2010, p. 98). Tal situação está caracterizada, principalmente, na identificação e preocupação por parte das professoras ao utilizar múltiplos métodos e metodologias de ensino para conduzir o acesso à informação por parte do discente.

Ainda em reflexão, parte-se do princípio de que a utilização de diferentes formas e narrativas para ensinar possibilita o desenvolvimento no aluno e o prazer pelo aprendizado, quando este considera também o imaginário envolto aos elementos do cotidiano de cada indivíduo. Nesse processo, o professor tem influência direta na educação do aluno e na sua formação para a cidadania. Nesta perspectiva, os desafios do ensino da Geografia Crítica permeiam a realidade das transformações da sociedade e o papel exercido por cada cidadão. Por isso, "[...] conhecer as necessidades dos usuários é fundamental pra que possamos planejar, construir, gerir e avaliar serviços e produtos informacionais." (FADEL et al., 2020, p. 26).

Percebe-se, então, a importância de trabalhar dentro da sala de aula uma Geografia ultrapassando as propostas isoladas dos livros didáticos, as atividades mecânicas e mnemônicas, pois "O conhecimento é, em primeiro lugar, um produto do ambiente em que é construído. $E$, em segundo, um produto cognitivo dos sujeitos." (WOIDA, 2010, p. 110). 
Nessa perspectiva, questionou como os alunos de hoje podem mudar a sociedade a partir dos assuntos tratados em sala de aula. Considera-se que o conhecimento tem como ponto de abordagens possíveis os

[...] elementos intangíveis e inerentes a quem o produziu, bem como elementos que pertencem ao ambiente, pois estão presentes em uma base comum e, por isso, subjacentes àqueles sujeitos que no ambiente estão incorporados. (WOIDA, 2010, p. 110 - 111).

Percebe-se uma relação entre a formação do conhecimento do aluno e o ato de considerar os elementos internos e externos ao ambiente escolar. Nesse sentido, a postura das professoras em sala de aula demonstra preocupação com o ensino dos alunos. Diante dessa identificação foi possível construir o Quadro 2.

Quadro 2- Relação do papel da professora com a formação do cidadão

\begin{tabular}{|c|c|c|c|c|}
\hline $\begin{array}{ll}\begin{array}{l}\text { Formação } \\
\text { do aluno }\end{array} & \begin{array}{l}\text { Característica } \\
\text { da Professora }\end{array}\end{array}$ & $\begin{array}{l}\text { Ativa e } \\
\text { criativa }\end{array}$ & Conscientizadora & Problematizadora & Questionadora \\
\hline Alunos críticos e participantes. & B & & & \\
\hline $\begin{array}{l}\text { Alunos com enriquecimento } \\
\text { pessoal. }\end{array}$ & & C & & \\
\hline Formação de alunos críticos. & & & A & \\
\hline $\begin{array}{l}\text { Aluno que pensa a sociedade } \\
\text { contextualizada. }\end{array}$ & & & & D \\
\hline
\end{tabular}

Percebe-se que cada professora tem sua forma de lecionar a disciplina de Geografia, porém, nenhuma foge do ponto principal de ensinar aos alunos de forma que conduza a construção de conhecimentos críticos e questionadores. Acredita-se que tal situação ocorre, pois, as professoras consideram que o aluno como "[...] um usuário precisa ter sua necessidade interpretada e ter condições semióticas para se apropriar da informação." (FADEL et al., 2020, p. 24).

No ambiente escolar, o aluno representa o usuário da informação e a apropriação de conteúdo, relações e reflexões conduzirá para todas de decisões nas relações sociais externas a escola. Tal situação pode ser interpretada, também, no Quadro 2, considerando a forma como cada professora ensina, pois, possibilita aos alunos uma formação participativa e uma aprendizagem dialógica. Nesse sentido, as professoras estão contribuindo para o desenvolvimento de novos conhecimentos onde,

[...] é necessário abordar uma Geografia reflexiva, capaz de considerar o papel dos atores sociais no seu espaço cotidiano, a fim de que professores e alunos possam compreender a importância dos conteúdos geográficos na sua vida. (FERNANDES; GEBRAN, 2010, p. 257).

Nota-se que as professoras priorizam a formação de um aluno crítico e, dessa forma, adaptam as concepções pedagógicas para reflexão e construção do conhecimento geográfico. Outro ponto observado ainda no Quadro 2 são as características das professoras, pois é possível identificar a preocupação em "[...] transpor os conteúdos acadêmicos para a Geografia 
escolar, a fim de eliminar o distanciamento entre as discussões teórico metodológicas da Geografia que ocorrem no âmbito da academia e as ações pedagógicas da escola básica." (FERNANDES; GEBRAN, 2010, p. 257).

Por fim, e enfatizando que "[...] é impossível não estudar os fenômenos relacionados à compreensão, à apropriação e ao uso da informação por parte dos indivíduos." (FADEL et al., 2010 , p. 16), nota-se que as práticas das professoras são criadas a sua forma de como construir o conhecimento juntamente com os alunos, que, sobre total influência do professor, cada aluno poderá ser mediador do seu próprio conhecimento a partir da informação vivenciada no ambiente escolar.

\section{CONSIDERAÇÕES FINAIS}

A pesquisa passou por uma releitura em que foi possível enfatizar as discussões da $\mathrm{Ci}$ ência da Informação, considerando o ambiente escolar. Assim, enfatizou-se o ensino da Geografia Crítica como o tema principal, ligando-a a realidade das professoras colaboradoras da pesquisa. Foi neste sentido que as respostas de cada uma nortearam os caminhos das interpretações.

Os resultados da pesquisa demonstraram que o ensino de Geografia, nos anos iniciais, permite criar uma base sólida em que a criança tem que pensar, entender e refletir. Para isto é necessário que haja clareza no conteúdo, logo ocorrerá um deslumbre por parte do aluno a esse componente curricular. Ao apresentar a forma metodológica utilizada pelas docentes, conclui-se que o desenvolvimento e a ampliação da cognição dos alunos estão relacionados à ação de aguçar a curiosidade pelo conteúdo ministrado.

Desta forma, para interpretar teoricamente as relações das professoras com a Geografia Crítica pelo viés da Ciência da Informação perpassou a discussão predominantemente pela compreensão da informação voltada para o ensino da Geografia e a mediação da informação, considerando a forma como as professoras pensam e ensinam a Geografia.

Ao inter-relacionar a discussão da Ciência da Informação com as concepções do ensino de Geografia, a partir das respostas obtidas durante o trabalho de campo, notou-se o envolvimento direto da informação e do ensino com a formação dos alunos.

Outro ponto abordado foi a relação do papel das professoras com a formação do cidadão, que demonstram preocupação com a formação de alunos críticos e participantes, bem como com o enriquecimento pessoal e, principalmente, com a formação de um aluno que compreende a informação em uma sociedade contextualizada.

Tem-se, assim, que os conteúdos da Geografia Crítica é uma das possibilidades a disposição do professor, que pode contribuir para o enriquecimento da formação do conhecimento individual e coletivo do aluno, proporcionando a construção crítica do pensar.

Nesses termos, a problemática foi respondida no momento que demonstrou a forma como as professoras colaboradoras, por meio da concepção de mediação, possibilitam a formação de cidadão crítico e atuante. Nesse mesmo sentido, o texto apresenta também uma reflexão da mediação da informação no ambiente escolar.

Por fim, essa releitura do trabalho de campo realizado inicialmente com as concepções da Pedagogia possibilita abrir caminhos para pesquisas futuras que perpassam pela multidisciplinariedade. 


\section{REFERÊNCIAS}

ALMEIDA JÚNIOR, O. F. Mediação da informação e múltiplas linguagens. Tendências da pesquisa brasileira em Ciência da Informação, Brasília, v. 2, n. 1, p.89-103, jan./dez. 2009. Disponível em: https://revistas.ancib.org/index.php/tpbci/article/view/170/170. Acesso em: 25 mar. 2020.

ALVES, A. J. O planejamento de pesquisas qualitativas em educação. Cadernos de pesquisa, São Paulo, v. 77, p. 53-61, maio 1991. Disponível em:

http://publicacoes.fcc.org.br/ojs/index.php/cp/article/view/1042/1050. Acesso em: 25 mar. 2020.

AMORIM FILHO, O. B. A pluralidade da Geografia e a necessidade das abordagens culturais. In: KOZEL. S., SILVA, J. C., GIL FILHO, S. F. (Orgs.). Da percepção e cognição a representação: reconstruções teóricas da Geografia Cultural e Humanista. São Paulo: Terceira Margem; Curitiba: NEER, 2007.

ARAÚJO, C. A. Á. Arquivologia, Biblioteconomia, Museologia e Ciência da Informação: o diálogo possível. São Paulo: Associação Brasileira de Profissionais da Informação (ABRAINFO), 2014.

BORTOLIN, S.; ALMEIDA JÚNIOR, O. F. Mediação oral literária: algumas palavras. In: VALENTIM, M. (Org.). Gestão, mediação e uso da informação. São Paulo: Cultura Acadêmica, 2010. Cap. 4, p. 85-103. Disponível em: https://repositorio.unesp.br/bitstream/handle/11449/110767/ISBN9788579831171.pdf?sequ ence=1\&isAllowed=y. Acesso em: 11 abr. 2020.

BRASIL. Ministério da Educação. Lei no 9.394, de 20 de dezembro de 1996 (LDB). Estabelece as Diretrizes e Bases da Educação Nacional. Disponível em:

http://www.planalto.gov.br/ccivil 03/leis/19394.htm. Acesso em: 11 abr. 2020.

BURKE, P. Uma história social do conhecimento - I: de Gutenberg a Diderot. Rio de Janeiro: Zahar, 2003.

BURKE, P. Uma história social do conhecimento - II: da Enciclopédia à Wikipédia.Rio de Janeiro: Zahar, 2012.

CARVALHO, A. M. G. A apropriação da informação: um olhar sobre as políticas públicas sociais de inclusão digital. Tese (Doutorado em Ciência da Informação) - Faculdade de Filosofia e Ciências da Universidade Estadual Paulista Júlio de Mesquita Filho UNESP, Marilia, 2010. Disponível em: https://www.marilia.unesp.br/Home/PosGraduacao/Cienciadalnformacao/Dissertacoes/carvalho amg do mar.pdf. Acesso em: 2 abr. 2020.

CHOO, C.W. A Organização do conhecimento: como as organizações usam a informação para criar significado, construir conhecimento e tomar decisões. São Paulo: SENAC, 2003. 
DINIZ FILHO, L. L. Fundamentos epistemológico da Geografia. Curitiba, IBPEX, 2009.

FADEL, B. at al. Gestão, mediação e uso da informação. In: VALENTIM, M. (Org.). Gestão, mediação e uso da informação. São Paulo: Cultura Acadêmica, 2010. Cap. 1, p. 13-31. Disponível em:

https://repositorio.unesp.br/bitstream/handle/11449/110767/ISBN9788579831171.pdf?sequ ence=1\&isAllowed=y. Acesso em: 11 abr. 2020.

FERNANDES, A. C.; GEBRAN, R. A. Geografia e prática social: configurações no espaço da escola. Acta Scientiarum: Education, Maringá, v. 32, n. 2, p. 255-262, 2010. Disponível em: http://periodicos.uem.br/ojs/index.php/ActaSciEduc/article/view/10126/10126. Acesso em: 25 mar. 2020.

FROHMANN, B. O caráter social, material e público da informação. In: FUJITA, M. S. L.; MARTELETO, R. M.; LARA, M. L. G. de (Org.). A dimensão epistemológica da Informação e suas interfaces técnicas, políticas e institucionais nos processos de produção, acesso e disseminação da informação. São Paulo: Cultura Acadêmica; Marília: Fundepe, 2013. p. 19-34. Disponível em:

http://webcache.googleusercontent.com/search?q=cache:aiGL zHommlJ:repositorios.questo esemrede.uff.br/repositorios/handle/123456789/829+\&cd=1\&hl=pt-

BR\&ct=clnk\&gl=br\&client=firefox-b-ab. Acesso em: 2 abr. 2020.

GIL, A. C. Como elaborar projetos de pesquisa. 4. ed. São Paulo: Atlas, 2002.

GIL, A. C. Métodos e técnicas de pesquisa social. 5. ed. São Paulo: Atlas, 1999.

GOLDENBERG, M. A arte de pesquisar: como fazer pesquisa qualitativa em Ciências Sociais. Rio de Janeiro: Record, 1999.

LARAIA, R. B. Cultura: um conceito antropológico. 17. ed. Rio de Janeiro, Zahar, 2004.

LIBÂNEO, J. C. Didática. São Paulo: Cortez, 1994.

MENEZES, W. A. CHIAPETTI, R. J. N. O Ensino de Geografia na contemporaneidade: o uso da literatura de cordel. Revista Brasileira de Educação em Geografia, Campinas, v. 5, n. 10, p. 235-257, jul./dez. 2015. Disponível em:

http://www.revistaedugeo.com.br/ojs/index.php/revistaedugeo/article/view/267/170.

MOREIRA, R. Pensar e ser em Geografia. São Paulo: Contexto, 2007.

PILETTI, C. Didática Geral. 23. ed. São Paulo: Ática, 2004.

ROSINI, A. M. Administração de sistemas de informação e a gestão do conhecimento. 2. ed. São Paulo: Cengage Learning, 2012.

SANTOS, M. Metamorfoses do espaço habitado: fundamentos teóricos e metodológicos da Geografia. 6. ed. São Paulo: Universidade de São Paulo, 2008. 
VESENTINI, J. W. et al. (Org.) Geografia e ensino: textos críticos. Campinas: Papirus, 1989.

VESENTINI, J. W. Geografia, natureza e sociedade: repensando a geografia. São Paulo: Contexto, 1997.

WOIDA, L. M., Contribuições teóricas e metodológicas da sociologia do conhecimento pra estudos de produção de conhecimento em contextos empresariais. In: VALENTIM, M. (Org.). Gestão, mediação e uso da informação. São Paulo: Cultura Acadêmica, 2010. Cap. 5, p. 105125. Disponível em:

https://repositorio.unesp.br/bitstream/handle/11449/110767/ISBN9788579831171.pdf?sequence=1 \&isAllowed=y. Acesso em: 11 abr. 2020. 